Çukurova Üniversitesi Mühendislik Mimarlık Fakültesi Dergisi, 29(1), 63-70 ss., Haziran 2014

Çukurova University Journal of the Faculty of Engineering and Architecture, 29(1), pp. 63-70, June 2014

\title{
İskenderun Demir Çelik (İSDEMIIR) Atık Çamurlarında Oluşan Çinkonun Eldesi
}

\author{
Yasin ERDOĞ ${ }^{*}{ }^{* 1}$, Raşit EREN $^{2}$ \\ M.K.Ü., Mühendislik Fakültesi, Petrol ve Doğalgaz Mühendisliği Bölümü, İskenderun/Hatay \\ M.K.Ü,. Fen Bilimleri Enstitüsü, İskenderun/Hatay
}

\section{Özet}

Türkiye'deki üç entegre demir çelik üreticisinden biri olan İSDEMIR'de üretim aşamaları sonucunda ortaya çıkan atıkların büyük kısmını yüksek firın (YF) tozu ve çamuru, çelikhane tozu ve çamuru ile yağlı hadde tufali tipindeki katı atıklar oluşturmaktadır. İSDEMİR'de çelikhane atıklarının büyük bir kısmı kullanılmamakta ve atık sahalarında stoklanmaktadır. Bu çalışma ile çinkonun gravimetrik ve metalürjik yöntemler ile yüksek demir içeren çamurdan ayrıştırılabilirliği araştırılmıştır.

Anahtar Kelimeler: İSDEMİR, Çamur atığı, Cüruf, Çinko.

\section{Recovery of Zinc in the Waste Sludge in Iskenderun Iron \& Steel Industry (ISDEMIR)}

\begin{abstract}
Blast furnace dust/sludge, steel mill sludge/dust and oily mill scale wastes constitutes the most of the production wastes which are produced as result of production steps at ISDEMIR (one of the three iron and steel producer company in Turkey). In ISDEMIR, big amount of steel mill and blast furnace flue gas cleaning wastes, oily mill scale, stack dust and steel mill slag are not used and stock as land fill at stockyards. In this article, separation of zinc from iron bearing sludge by gravimetric and metallurgical methods was studied.
\end{abstract}

Keywords: ISDEMIR, Waste sludge, Slag, Zinc

\footnotetext{
* Yazışmaların yapılacağı yazar: Yasin ERDOĞAN, M.K.ய̈., Mühendislik Mimarlık Fakültesi, Petrol ve Doğalgaz Mühendisliği Bölümü, Iskenderun/Hatay. erdogan@mku.edu.tr.
} 


\section{GíRiş}

İnsan faaliyetleriyle ortaya çıkan atıkların havaya, suya ve toprağa salınarak toprağın kimyasal, fiziksel ve biyolojik özelliklerini bozmasıyla çevre kirliliği ortaya çıkmıştır. Özellikle sanayi devriminden sonra doğal kaynaklardan da faydalanan teknolojiler geliştiren insanoğlu, çevre kirliliği ile ekolojik dengeyi süratle bozmuş ve çevre sorunları yaratmıştır. Ancak bu sorunların insan sağlı̆̆ını olumsuz yönde etkilemesi çevre bilinci olgusunu ortaya çıkmıştır [1].

Kore, Tayvan ve Meksika'da yeni kurulan ve kurulmakta olan tesislerin çoğu çevre koruma önlemlerini kuruluş aşamasında almaktadır. Çin'de çevre kirliliği kontrolü uygulamaları yeterli seviyelerde olmamasına rağmen yeni kurulan tesislerde eskiye nazaran çevresel konular daha fazla dikkate alınmaktadır. Doğu Avrupa ve Rusya'nın çelik üretim miktarı önemli ölçüde azalmasına rağmen üretimin eski teknolojilerle gerçekleştirilmesinden ve bu bölgelerdeki yerel çevre kanunlarının yeterli yaptırımlara sahip olmamasından dolayı tesislerde ortaya çıkan atıklar hem çalışanların sağlığı hem de üretimin gerçekleştirildiği bölgelerin ekolojik dengesi üzerinde ciddi sorunlar yaratmaktadır [2].

Cevherden başlayarak çelik üreten entegre demir çelik tesislerinden ortaya çıkan yüksek firın toz ve çamuru, çelikhane toz ve çamuru ve yağlı hadde tufali gibi atıkların içerdiği $\mathrm{Zn}, \mathrm{Pb}$ ve $\mathrm{Cd}$ gibi metaller düşük seviyelerde olduğundan, bu metallerin geri kazanımı ekonomik olmamakla beraber doğaya verildiklerinde çevreyi kirletecek seviyelerdedir. Son yıllarda entegre demir çelik tesislerinden ortaya çıkan bu tip atıkların hem çevreye zarar vermeden bertaraf edilmesi hem de içerdiği demir oksitlerin kazanılmasını amaçlayan çalışmalar yoğunluk kazanmıştır.

\section{2. ÖNCEKİ ÇALIŞMALAR}

\section{1. Çalışma Alanı}

Ülkemizin kuruluş tarihi itibariyle üçüncü, uzun ürün üretim kapasitesine göre en büyük entegre demir ve çelik fabrikası olan İSDEMIR, 2008 yılında devreye aldığı 3,5 milyon ton/yıl sicak haddeleme kapasitesiyle Türkiye'nin uzun ve yassı ürün üreten tek entegre tesisidir. İSDEMIR, 3 Ekim 1970 tarihin de Türkiye'nin güneyinde Akdeniz kıyısında, İskenderun'a 17 km mesafede, Payas (Yakacık) yöresinde kurulmuştur (Şekil 1). Kurulduğu tarihte sosyal tesisleriyle birlikte toplam 16,75 milyon $\mathrm{m}^{2}$ alan (fabrika alanı 6,8 milyon $\mathrm{m}^{2}$ ) üzerine kurulmuştur.

1975 yılında 1,1 milyon ton/yıl çelik blum üretim kapasitesiyle işletmeye alınan İSDEMİR, yapılan I. tevsiatla 1985 yllından itibaren 2,2 milyon ton/yıl üretim kapasitesine çıkarılmıştır [3]. Uluslararası kalite standartlarında Pik, Blum, Kütük, İnşaat Çelikleri gibi uzun mamul üretilmesi amaciyla kurulan İSDEMIR tesislerinde koksinter - yüksek firın - çelikhane - sürekli döküm ve sicak haddeleme prosesleriyle üretim yapılmaktadır. Ürünler iç piyasa ile başta Güney Avrupa ve Orta Doğu ülkeleri olmak üzere tüm dünya ülkelerine ihraç edilmektedir. Yapılan Modernizasyon ve Dönüşüm Yatırımları (MDY) ile uzun ürünlerin yanı sıra 2008 yılı Ağustos ayından itibaren yassı ürün üretimine de başlanmıştır. İsdemir'in esas ürün gamında pik, kütük, kangal, slab, sıcak haddelenmiş rulo ve levha bulunmaktadır. $\mathrm{Bu}$ ürünlerin yanı sıra kok kömürü, oksijen, azot, argon, amonyum sülfat, granüle cüruf, katran ve benzol gibi yan ürünler de elde edilmektedir.

İSDEMİR, sürekli gelişmeyi, yeni teknolojiler kullanmayı, çevreye olan duyarlılığı ile öne çıkan güzide kuruluşlarımızdan biridir. 2003 y1lı içerisinde planlanan ve 2004 yılı içerisinde başlayan Modernizasyon ve Dönüşüm Yatırımları (MDY) tamamlanarak, başlangıçta 2,2 milyon ton/yıl olan sıvı çelik kapasitesi 5,3 milyon ton/yıl seviyesine çıkartılmıştır. Bununla beraber, uzun ürünün yanı sıra ağırlıklı olarak yassı mamul üretimi de yapılmaktadır. 2012 yılı içerisinde İSDEMİR' in Modernizasyon ve Dönüşüm Yatırımları tamamlanmıştır.

\subsection{Atıklar}

İsdemir genelinde çelikhane konvertörlerinde galvanizli hurda kullanımına bağlı olarak 
çelikhane gaz temizlemeden gelen çamurlu sularda çinko miktarının aşırı yükselmiş olması (ort.\%1,55) ve \%3-4 gibi değerlere çıkabilmesi sinter harmanına giren çinkonun artmasına neden olmaktadır. Bu yüksek çinkolu çamurun sistemde değerlendirilememesi çevre kirliliğiyle birlikte \%50-55 $\mathrm{Fe}$ tenörlü cevherin değerlendirilememesine neden olmaktadır. Tesislerde çamurun kurutulmasiyla elde edilen şlam, yüksek Zn içeriği sebebiyle sinter harmanına ilave edilmemekte, harman sahasında ayrı bir bölüme istif edilmektedir (Çizelge 1). Belirli dönemlerde çimento sektörüne satılmış olan ürün tenörlü cevher olarak kabul edilmekle birlikte, günde 200-220 tonluk bir miktarda üretilen malzeme kullanılamamakta, stoklamada problem teşkil etmektedir. İşletmede kapasite artırma çalışmaları tamamlanmış olup, oluşan çamur miktarı da iki kat artmıștır. Mevcut atık düzenli satılamazsa stoklama sorunu başlayacaktır [4].

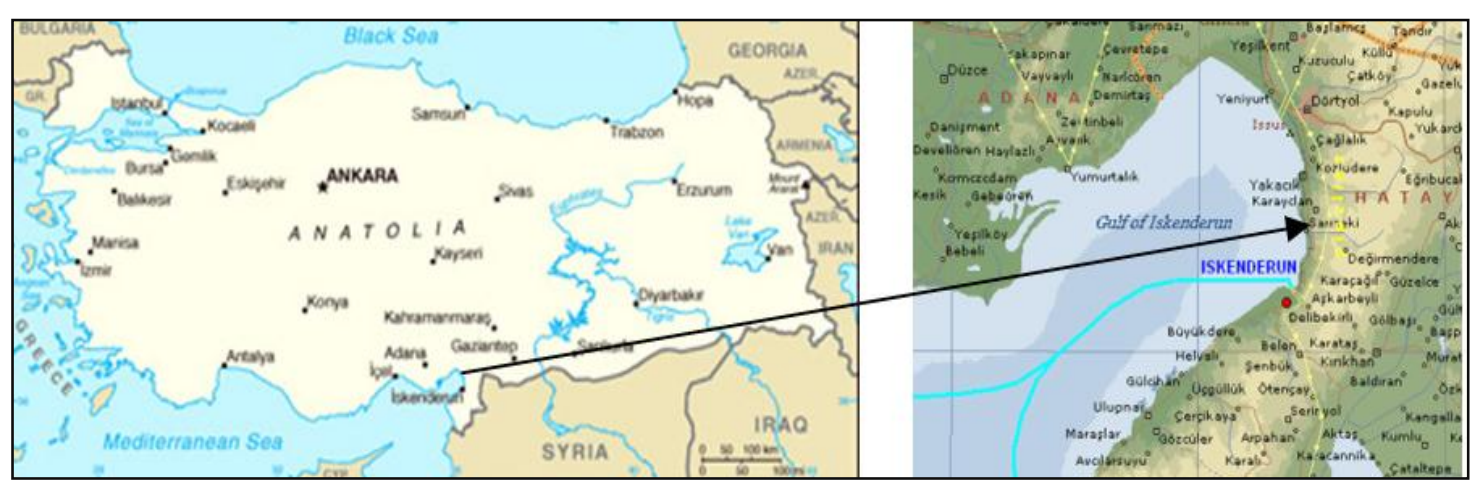

Şekil 1. İsdemir yerbulduru haritası

Çizelge 1. Çamurun kimyasal içeriği (İsdemir, 2011)

\begin{tabular}{|l|l|l|l|l|l|l|}
\hline \multicolumn{7}{|l|}{ Yüksek Fırın Çamurunun Kimyasal Bileşimi } \\
\hline Empürite(\%) & $\mathrm{Fe}$ & $\mathrm{Al}_{2} \mathrm{O}_{3}$ & $\mathrm{Zn}$ & $\mathrm{K}_{2} \mathrm{O}$ & $\mathrm{Na}_{2} \mathrm{O}$ & $\mathrm{SiO}_{2}$ \\
\hline İçerik (\%) & 31,03 & 2,67 & 1,79 & 0,38 & 0,47 & 7,78 \\
\hline Kullanım Yeri & \multicolumn{6}{l|}{ Stoklanmaktadır. } \\
\hline
\end{tabular}

\section{METOD}

Çelikhane ve yüksek firın çamurları demir içeriklerinden dolayı değer taşımalarına rağmen, yüksek çinko içerikleri nedeniyle yüksek firın prosesini etkilemekte ve çok ince taneli olmalarından dolayı geri kazanımları kolay olmamaktadır. Bunların doğrudan sinter ya da yüksek firınlarda kullanımları mümkün değildir. Yüksek firınlara şarj edilen malzemenin içerisindeki çinko, sıvı ham demir ve cürufa geçmez. Çinko bileşikleri yüksek firının alt kısımlarında indirgenerek gaz ile birlikte küçük çinko veya çinko oksit parçaları halinde uçar. Yüksek firın içinde gaz halinde uçuşan çinko parçacıkları, fırının üst cidarlarında kalın çinko oksit tabakaları oluşturmaktadır.

$\mathrm{Zn}+\mathrm{CO}_{2} \rightarrow \mathrm{ZnO}+\mathrm{CO}$

$\mathrm{ZnO}$, fırının üst cidarlarında tabakalaşma yapacağ gibi, yüksek firın refrakteri içindeki alüminayla reaksiyona girerek tuğlaların parçalanmasına, skafold (firın duvarlarına yapışarak katılaşan iskeletimsi yapılar) oluşumuna neden olmaktadır. Buna bağlı olarak malzemenin inişini engelleyip askılanmaya yol açmakta, yüksek firında hacim daralmasına ve sonuç olarak da hem üretim kaybına hem de yakıt oranlarının artmasına yol açmaktadır [4]. 
Çinkonun mevcudiyeti yüksek firın içerisinde fayalit ve gersinit oluşmasına yardıme olur. Fayalit ve gersenit yüksek firında indirgenmesi zor ve üretim kayıpları meydana getiren bileşiklerdir. $\mathrm{FeO}$, buharda tuğlalarda çatlaklar meydana getiren katalizör görevi yapar. Karbon yardımıyla tuğlalarda açılan çatlaklara alkaliler ve ZnO'ler dolarak tuğlaların yumuşama sıcaklıklarını düşürür ve daha sonra tuğlalarda hacim genişlemesi olur ve tuğlalar parçalanır. Şarj malzeme içindeki $\mathrm{Zn}$ ortamdaki alkaliler ile müşterek hareket ederek tuğlalar üzerindeki zararlı etkilerini artırır.

Yüksek firın işletmesindeki bu olumsuz etkisinden dolayı şarj malzemelerin içerisinde firına giren çinkonun miktarı $0,180 \mathrm{~kg} / \mathrm{TSM}$ (Ton Siv1 Metal)'nin altında tutulmalıdır. Şarj malzemeleri ile firına giren Zn'nun yaklaşık \% 70 'i sinter ile girmekte, bu nedenle sinterdeki Zn kontrolü büyük önem taşımaktadır.

\section{ARAŞTIRMA BULGULARI}

Entegre demir çelik tesislerinde nihai üretim süreçleri içerisinde oluşan ve stoklanan, yüksek firın, çelikhane çamurları ve tüm toz toplama sistemlerinden çıkan Zn içerikli atıkların kazanımına yönelik çalışmaları başlıca dört grup altında toplamaktadır. Bunlar; Hidrosiklon, Aglomerasyon, Hidrometalurji ve Pirometalurji'dir. $\mathrm{Bu}$ yöntemlerle işlem gören atıklar sinter fabrikalarına, yüksek firınlara, çelikhane konvertörlerine ve ark ocaklarına şarj edilerek geri dönüşümü sağlanmaktadır [4].

\subsection{Hidrosiklon Ayırma Yöntemi}

Hidrosiklon ile ayırma yöntemi günümüzde özelikle çinko içeriği yüksek olan çamurlara uygulanmaktadır (Şekil 2). Düşük çinko yüzdesine sahip iri taneler hidrosiklonun altında toplanmakta, yüksek çinkolu çok ince taneler ise siklonun üstünden ayrışmaktadır (Çizelge 2).

Elde edilen ürün sinter fabrikalarında, briket hammaddesi olarak kullanılmaktadır.

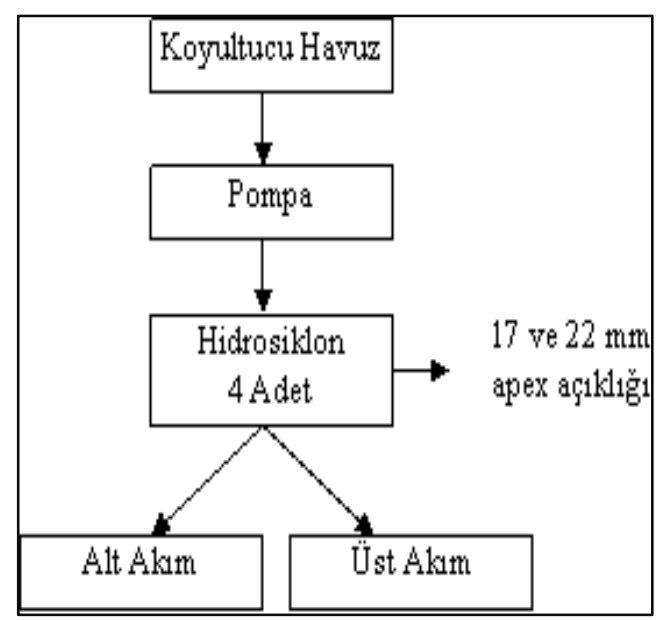

Şekil 2. Hidrosiklon deneme akım şeması [3].

Bu yöntem Japonya'da bulunan Kawasaki Steel'de ve İngiltere'de bulunan Corus'un Scunthorpe Works tesislerinde başarıyla uygulanarak 20,000 ton/yıl yüksek firın çamuru geri kazanılmaktadır. Ancak geride kalan yüksek çinkolu çamur ise sorun oluşturmaya devam etmektedir.

İsdemir'de yüksek firından ve çelikhane gaz temizleme ünitelerinden gelen çamur malzemesi üzerinde yapılan hidrosiklon denemelerinde; tane fraksiyonu ile $\mathrm{Fe}$ ve $\mathrm{Zn}$ tenör ve içerik dağılımına baktığımızda, çinkonun \% 47,17'lik kısmının -38 $\mu \mathrm{m}$ altında olduğu görülmüștür [5]. Bu tane sinıfinda Fe'nin \%19,99'u ve Zn'nin \%55,96'sının bulunduğu, çok ince boyutta olduğundan dolayı yoğunluğa dayalı yöntemlerle zenginleștirilmesinin zor olduğu görülmektedir. Ayrıca, Fe ile $\mathrm{Zn}$ tenörlerinin birbirleriyle paralel şekilde tane fraksiyon dağılımında değiştiği ve birbiriyle kenetli bir şekilde bulunduğu görülmüştür.

Yapılan hidrosiklon test çalışmaları neticesinde, çamurdaki çinko miktarı azaltılırken, çinko ile beraber demirin de azaldığı görülmüştür.

Hidrosiklon yöntemi ile çamurdaki çinkonun kazanılmasına çalışılmış fakat istenilen sonuçlar alınamamıștır. 
Çizelge 2. Çamurdaki $\mathrm{Zn}$ ve Fe tenör ve dağı̆lımı [4].

\begin{tabular}{|l|l|l|l|l|l|}
\hline $\begin{array}{c}\text { Dağılım } \\
(\mu \mathrm{m})\end{array}$ & \multirow{2}{*}{$\begin{array}{c}\% \\
\text { Ağılık }\end{array}$} & \multicolumn{2}{|c|}{ Tenör } & \multicolumn{2}{c|}{ İcrik Dağ1lımı } \\
\cline { 3 - 6 } & & $\% \mathrm{Fe}$ & $\% \mathrm{Zn}$ & $\% \mathrm{Fe}$ & $\% \mathrm{Zn}$ \\
\hline 106 & 41,10 & 49,04 & 1,46 & 39,37 & 35,23 \\
\hline$-106+75$ & 5,28 & 47,38 & 1,32 & 4,89 & 4,11 \\
\hline$-75+53$ & 2,54 & 44,40 & 1,03 & 2,21 & 1,53 \\
\hline$-53+45$ & 2,54 & 46,61 & 1,46 & 2,32 & 2,18 \\
\hline$-45+38$ & 1,37 & 45,82 & 1,23 & 1,23 & 0,99 \\
\hline-38 & 47,17 & 54,26 & 2,02 & 49,99 & 55,96 \\
\hline
\end{tabular}

\subsection{Aglomerasyon Yöntemi}

Aglomerasyon ise yüksek basınç ve düşük sicaklıkta briketleme ve peletleme işlemlerini kapsar. Çamur tozu, kömür ve bağlayıcılar ile birlikte orantılı olarak yüksek yoğunluklu karıştıııcıyı besleyen taşıyıcı bantlara aktarılır. Karıştırıcı, soğuk briketleme öncesi ham malzemenin tam karışımını sağlayacaktır. Karıştırıcıdan çıkan ham malzeme karışımı briketlemeye gönderilirken, fazla malzeme ise karıştırıcı ünitesi beslemesi için geri gönderilir.

Briketleme ünitesinde karışım preslerde sıkıştırılarak briketler oluşturulur. Briketleme sonrasi istenilen boyutun altında olanlar karıştırıcıya geri gönderilir.

Bu yöntemle elde edilen ürünlerde yüksek firnn ve konvertöre şarj açısından istenen fiziksel özellikler sağlanabilmekte ancak kimyasal açıdan herhangi bir işlem yapılmadığından yüksek çinko ve alkali sorun olmaya devam etmektedir. Briketleme yöntemi tüm dünyada yoğun olarak kullanılmakta, yüksek çinko içerikli toz ve çamurlardan yapılan briketler konvertör ya da ark ocaklarına, düşük çinkolu içeriğiyle yapılan briketler ise yüksek firınlara beslenmektedir. Ancak kullanıldıkları yerlerde proses veriminin düşmesine neden olmakta özellikle de yüksek firınlarda daha büyük sorunlara yol açabilmektedirler. Aglomerasyon yönteminin en uygun kullanım alanları konvertörler ve ark ocaklarıdır [6].

\subsection{Hidrometalurji Yöntemleri}

Hidrometalurji yönteminde, sülfür bileşimli konsantre ya kuvvetli sulu çözücü ortam temin edilmek suretiyle doğrudan çözeltilir veya önce kavurmak suretiyle asidik ortamda kolay çözünür yapıya dönüştürülür ve sonra çözeltilir [7]. Çinko için iki değişik liç yöntemi vardır. Bunlar; sürekli yöntem ve kesikli yöntemdir. Bunlardan en çok iki veya üç kademede uygulanan kesikli yöntemler yaygındır. $\mathrm{Bu}$ yöntemlerde -325 mesh seviyesinde öğütülen kalsine, havalı karıştırma yapan korozyona dayanıklı tanklarda liç edilir.

Çözeltiye geçen çinko, her iki hidro yöntemle de elektrolizle kazanılır. Gerek pirometalurjik yoldan gerekse hidrometalurjik yoldan çinkonun kazanılabilmesi için, öncelikle bileşimin oksit hale dönüştürülmesi gerekmektedir.

$\mathrm{ZnS}+\mathrm{O}_{2} \rightarrow \mathrm{ZnO}+\mathrm{SO}_{2}$

Meydana gelen $\mathrm{ZnO}$ bileşiğinden pirometalurjik yöntemle çinko üretilecekse karbonla redükleme,

$2 \mathrm{ZnO}+\mathrm{C} \rightarrow 2 \mathrm{Zn}+\mathrm{CO}_{2}$ işlemi yapılır.

Hidrometalurjik yöntemle çinko üretilecekse sülfürik asitli sulu ortamda çözeltme işlemi yapılır.

$\mathrm{ZnO}+\mathrm{H}_{2} \mathrm{SO}_{4} \rightarrow \mathrm{ZnSO}_{4}+\mathrm{H}_{2} \mathrm{O}$

Hidrometalurji yönteminde çözücü ile ayırma işlemleri yapilmakta ancak çok başarılı olunamadığından fazla yaygınlaşamamıştır. Çinko ile birlikte ekonomik oranda kurşun, bakır, gümüş gibi elementleri de içeren kompleks malzemeler için hidrometalurjik yöntemler daha çekici hale gelmiştir. Çinko geri kazanımını sağlayan liç teknolojisi alternatiflerinden bir tanesi Waelz teknolojisidir. $\mathrm{Bu}$ teknolojide, çinko içerikli malzemeyi 1sıtmak için içinden sicak gaz geçen döner firın kullanılmaktadır. $1100{ }^{\circ} \mathrm{C}$ 'nin üstünde bir sicaklıkta metal oksitler indirgenerek çinko ve kursunun atmosfere karışması sağlanır.

Çinko oksit ve kursun oksit elde etmek için prosese hava verilerek gaz ortamında metal buharlarının oksitlenmesi sağlanır. Daha sonra 
oksit karıșımı gaz temizleme sisteminde ayrıştırılmak üzere gazlarla birlikte fırından çekilir. Gaz çıkış derecesi $650-750{ }^{\circ} \mathrm{C}$ 'dir. İlk aşamada, iri taneli parçacıklar toz odasında çökelir. $\mathrm{Bu}$ kısım doğrudan giriş kısmına geri döndürülür. Bir sonraki aşamada sıcak işlem gazları soğutulur. Ürünün ilk kısmı gaz soğutma aşamasında geri kazanılsa da oksitlerin büyük çoğunluğu gaz çıkışından torba filtreleri içinde filtrelenir. Temiz gazın içerisindeki gaz oranı $10 \mathrm{mg} / \mathrm{Nm}^{3}$ 'den azdır. Arıtılmış gazlar baca içerisinden tüm sistemdeki saklama koşullarını kontrol etmek amacıyla bir fan aracılığıyla çıkarılır. Toplanılan katılar çinko geri kazanımı için liç düzeneğine aktarılır.

Seyreltilmiş sülfürik asit liç düzeneğine aktarılarak yoğunlaştırma ve filtreleme işlemlerinden geçirilir. Filtrelenmiş çözelti geleneksel çinko tozu çökelimi yöntemiyle arıtılır. Çinko metali elektro kazanım yoluyla geri kazanılır ve katotlar eritilerek ulusal ve uluslararası satış için külçeler halinde hazırlanır [6].

\subsection{Pirometalurjik Yöntemler}

Pirometalurji yöntemi ise indirgeme esasına dayanmaktadır. Piro esaslı üretimde çamur malzemesi kavurma ile oksit yapıya dönüştürülmesi gerekir. Çinko oksit sonra retort veya düşey firında, kömürle metalik çinkoya redüklenir. Atık toz ve çamurlar harmanlanarak kurutulmakta peletlenerek, briketlenerek ya da doğrudan toz olarak döner firınlara beslenmektedir. $\mathrm{Bu}$ firınlarda redüklenerek istenmeyen empüriteler yapıdan uzaklaştırılmakta ve sonuçta indirgenmiş ürün elde edilerek sinter, yüksek firın, konvertör ya da ark ocaklarında sorunsuz kullanılabilmektedir.

Düşey retort yönteminde çinko kazanma verimi \%96'ya çıkarılabilmiştir. Yatay retort yöntemine göre hem çinko kazanma verimi yüksek, hem de yakıt ve işçilik masrafları daha azdır [7]. Değişik isimler altında metalürjik pek çok teknoloji mevcut olup atıkların sorunsuz kazanımı için metalürjik yöntemler nihâi çözümdür. Ancak, gerek yatırım gerekse işletme maliyetlerinin yüksek oluşundan dolayı bu yöntem yaygınlaşamamaktadır. Demir çelik tesisleri en ekonomik yollarla atıklarını azami ölçüde geri kazanabilmekte olup, yüksek çinko oranlı kazanamayacakları atıklar için redükleme yöntemlerini kullanmışlardır. İndirgeme işleminin yapıldığı firınlar şekilsel olarak ikiye ayrılmaktadır. Bunlar; döner yatay firın ve döner dairesel firındır. İlk geliştirilen ve uzun yıllar kullanılan şekil döner yatay firın olup, teknolojinin geldiği son aşama ise döner dairesel firın şeklidir.

Döner Tabanlı Ocak: Döner tabanlı ocak (DTO) besleme sistemi briketleri döner taban üzerine tek sıralı olarak yerleştiren, düzenleyen ve seviyelendiren bir sistemdir. Redüksiyon operasyonunun başarısı büyük oranda bu donanımın etkili çalışmasına bağlıdır. Döner taban üzerinde briketlerin homojen ve sürekli dizilimi fasmelt teknolojisinin verimliliği için anahtar teknolojidir [8].

ZincOx firmasının İzmir Aliağa'da inşa edeceği tesiste 200.000 ton/y1l malzeme besleme durumu için, net diş çapı yaklaşık $31,9 \mathrm{~m}$. ve etkin taban genişliği $3,75 \mathrm{~m}$ olan DTO kullanacaktır.

Üretim hızına bağlı olarak bu ocak 26,7 ton/saat hammadde işleyecek kapasitede tasarlanmaktadır. $\mathrm{Bu}$ durum 7.500 ton/saat işletme kapasitesine göre 200.000 ton/y1l atık beslemesine eşittir. Briketlerin indirgenmesi ve çinko ayrıştırması işlemleri DTO'da yapılmakta ve bir kaç bölümden oluşmaktadır. Bunlar; reaksiyon bölümleri, soğutma bölümü ve besleme/boşaltma bölümüdür. Midrex tarafından tasarlanan tesiste proses için gerekli enerji, brülörler ve ikincil yanma vasıtası ile sağlanacaktır.

Ocağın tabanındaki dönen besleme/boşaltma bölümü, briket besleme ve indirgenmiş briket çıkışını başarıyla yürütmek amacıyla 2 adet su soğutmalı şaft üzerinde hareket edecektir. Ocak tabanı döndükçe briketler 1 sınma ile $1290^{\circ} \mathrm{C}$ 'yi aşan sıcaklıklara kadar isıtılacak ve metal oksitler metalik faza indirgenecektir.

İndirgenme sırasında briketlerden çıan karbonmonoksit, çinko ve bakır briketlerin hemen üzerinde koruyucu, indirgen bir atmosfer oluşmasını sağlayacaktır. Proses tarafından açı̆̆a çıkan karbonmonoksit ve kömür buharı ocağın 
yakıt ihtiyacında kullanılacaktır. Yakıcı alev özellikleri ve ikincil hava enjeksiyonu 1S1 transferini optimize edecek, oluşan yakıtın etkili kullanımını destekleyecek ve direk redüklenmiş demirin (DRD) yeniden oksitlenmesini en aza indirebilecek şekilde tasarlanmıştır. $\mathrm{Bu}$ tasarım Kobe Steel şirketinin Computational Fluid Dynamics (Akışkan mekaniği modellemesi) programı tarafindan modellenerek optimum olarak tasarlanmıştır.

Proses sonucunda elde edilen demir, doğrudan redükte edilmiş demir olarak tanımlanmaktadır. Formüllerdeki karbon kaynağı kömürdür. Yüksek sicaklıkta çinko, kurşun ve diğer metaller önce redüklenerek metal fazına ve metal olarak gaz fazına geçecektir.

Döner Tabanlı Ocak Boşaltımı: Demiri redükte edilmiş ve metalleri alınmıs briketler sistemden spiral boşaltım yapısı kullanılarak çıkarılacaktır. $\mathrm{Fe}_{2} \mathrm{O}_{3}$ ve $\mathrm{Fe}_{3} \mathrm{O}_{4}$ 'ün indirgendiği briketler için iki opsiyon bulunmaktadır. Bunlar; DTO'dan çıkartılan yüksek metal içerikli DRD briketleri grafit elektrotlu elektrik firına aktarılması ve bu firında 5.000 ton/yıl kireç ve 1.500 ton/yıl kömür ile karıştırılarak eritilmesidir.

Fırın içerisinde oluşan gazlar DTO'a geri verilerek kapalı devre üretim sağlanır.

Bu proses sonucunda ürün olarak çelik sanayisinde kullanılacak pik demir, atık olarak cüruf elde edilir. Ürünler demir çelik endüstrisine satılabilecektir. Yaklaşık 55.000 ton/yıl pik demir elde edilebilecektir. Yılda yaklaşık 49.000 ton cüruf belirlenecek bir alanda depolanacaktır. Cüruf inert atık olacaktır.

DTO'dan elde edilen DRD, yüksek firınları kullanan entegre demir-çelik endüstrisine satılabilecek kalitededir. Satılma opsiyonunun gerçekleşmesi durumunda elektrikli eritme firını kullanılmayacaktır. Eğer DRD satılırsa DTO' dan briketler, briket soğutma birimine aktarılır. Burada briketler sıkıștırılarak hava ve oksijenin briket içine sızıp demiri tekrar oksitlemesi engellenecektir. Soğutulan briketler ürün deposuna radyal taşıyıcılar aracılığı ile aktarılacaktır.
Buradan da potansiyel alıcılara taşınabilecektir. Gerek briketlemede gerekse peletlemede geliştirilecek konular içinde ucuz bağlayıcıların araştırılması gelmektedir. Bağlayıcı olarak kullanılan hammaddeler bentonit, melastır. Fırınlarda ise yakıt olarak kömür, doğal gaz, kok gazı, katran ve atık yağlar kullanılabilmektedir. DTO teknolojisi Japonya'da iki ayrı çelik tesisinde kullanılan bir teknolojidir. $\mathrm{Bu}$ tesisler 1995 ve 2000 tarihlerinden bu yana çalıştırılan Kakogawa ve Nippon Steel üretim tesisleridir.

Fasmelt prosesi ise toz kömürü redükleyici olarak kullanıp, elektrik ark ocağı tozunun (EAOT) ve demir-çelik fabrikalarından kaynaklanan tufali karıştırarak önce DRD ile çinko oksit elde edecek ve daha sonra elektrik ocağı ile DRD eritilerek pik demir üretecek bir prosestir. $\mathrm{Bu}$ işlem sırasında oluşacak çinkonun çinko oksit, demirin ise pik demir olarak kazanımı hedeflenmektedir. Uygulanacak Fasmelt projesi ile $1.290^{\circ} \mathrm{C}$ sicaklık altında redükte edilen demirden pik demir elde edilirken, bu sıcaklıkta buharlaşan çinko ve kurşunun soğurken oksitlenmesi sonucunda oluşacak tozların torba filtrede tutulup toplanması ile çinko oksit elde edilmektedir.

Önerilen proses sonucu inert olan cüruf katı atık olarak elde edilirken, prosesden sivı atık meydana gelmemektedir. Yanma ortamının düzenlenmesi ile $\mathrm{SO}_{\mathrm{x}}, \mathrm{NO}_{\mathrm{x}}$, dioksin gazlarının çıkışı sürekli kontrol altına alınacaktır.

$\mathrm{Bu}$ tesiste, 5.000 ton kireç kullanılacaktır. Tesiste gerçekleştirilecek üretim ise yaklaşık 55.000 ton/y1l pik demir ve 80.000 ton/yıl çinko oksit şeklindedir. Ayrıca 49.000 ton/yıl cüruf elde edilecektir. Böylece prosesten toplam çıtı miktarı yaklaşık 184.000 ton/yıldır. Aradaki fark kömürün yanmasından ve indirgemeden dolayı oluşacak karbondioksit ve su buharı içermektedir.

\subsection{Primus Teknolojisi}

Bu teknoloji fasmelt teknolojisinde olduğu gibi toz kömürünü redükleyici olarak kullanmakda, EAOT ve tufali karıştırarak DRD ile çinko oksit elde edilmeltedir. $\mathrm{Bu}$ işlemler sonrasında da elektrik ocağı ile DRD eritilerek pik demir üretilmesi 
presibine dayanan bir prosestir. Fasmelt prosesinden farkı üst üste oturtulmuş döner firın içermesidir [6].

\section{SONUÇLAR}

Yapılan çalışmalar sonucu yüksek firın çamurlarından $\mathrm{ZnO}$ uzaklaştırılmasında liç yönteminin istenilen verimde gerçekleştirilmesi sağlanmıştır. YF çamurunun içeriğinde $\% 40$ gibi yüksek oranlarda bulunan ve bir enerji kaynağ1 olan karbon, hidrometalurjik yöntemde ayrışmaya uğramayıp, çamurda $\mathrm{Zn}$ ve Pb'nin oranı \%0,1'in altına çekilmiştir.

Ayrica literatürde yer almayan yeni bir sementasyon yöntemi olarak $\mathrm{CaCO}_{3}$ katılması ile kostik çözeltisinin büyük ölçüde yeniden kullanılması konusunda başarı elde edilmiştir.

Diğer yandan kostik yalnızca $\mathrm{ZnO}$ formundaki çinkoyu çözebilmiştir. Çelikhane ve karışım çamurlarından ferritik yapının uzaklaştırılması denemelerine pirometalurjik yöntemle devam edilmiştir.

YF çamurunun $\mathrm{NaOH}$ çözeltisiyle çinkosuzlaştırılması ve ardından aglomere edilerek sinterde kullanımı kok girdisi yönünden de avantaj sağlayacaktır. ÇH çamurları ve karışım çamurlarının eritilmesi için pirometalurjik yöntem tercih edilmiştir.

Yağlı tufalin yağından arındırılması konusunda da maliyeti düşük alkali çözücülerle (sodyum bi karbonat, soda külü v.s.) saha çalışmalarına devam edilmiştir. Yapılan denemelerde görülmüştür ki yağlı tufal ihtiva eden ve belirli bir akışkanlığa haiz sulu çözeltiye mekanik bir kuvvet uygulandığında, yağ tufalden ayrılmıştır.

Yağlı tufalin yağından arındırılması için tasarlanacak tesis üç kademeli düşünülmüştür. Çarpma, sürtünme, aşındırma veya santrifüj prensibi ile çalışan birinci reaktörde tufal yağdan ayrıştırılarak, ikinci reaktörde su ile emülsiyon yapmış tufaldeki yağ üsten süpürme yöntemi ile alınmıştır. Üçüncü ve son reaktörde tufal nihai olarak yıkanıp temiz olarak sistemi terk etmiştir.
İkinci ve üçüncü aşamalarda yağ üstten alındıktan sonra su filtre edilmiştir.

Yağlı tufalin direkt sinter üretim tesisinde kullanılabilmesi için aşağıdaki alternatif yöntemler denenecektir. Püskürtme yönteminde akışkanlığı düşük olan yağlı tufal ve katran $\left(70-80^{\circ} \mathrm{C}\right)$ bir mikserde karıştırılıp, öğütücü tipli bir pompa vasıtasıyla püskürtme işlemine tabi tutulmuştur.

\section{KAYNAKLAR}

1. Szekely, J., 1996. Steelmaking and Industrial Ecology-Is Steel a Green Material, ISIJ International, Vol 36, No 1, p 121-132.

2. Philipp, J., Endell, R., 1996. How German Steel Industry is Managing Waste Disposal, Steel Techolonogy, p 275-279.

3. İsdemir, 2008. Sinter ve Hammadde Manipülasyon Müdürlüğü Tanıtım ve İntibak Eğitimi El Kitabı.

4. İsdemir, 2011. Etüt Plan Proje Müdürlüğü, Sinter ve Hammadde Maniplasyon Müdürlüğü Raporu.

5. Erdemir, 2010. Erdemir Ar-Ge, İsdemir Sinter ve Hammadde ve Maniplasyon Müdürlüğü ve Erenco A.Ş Atık Değerlendirme Takım Çalışması Raporu.

6. Anonim, 2012. Yüksek Çinkolu Çelikhane Çamurunun Değerlendirilmesi ile İlgili Erdemir ve İsdemir'de Yapılan Çalışmalar Hakkında Bilgi Notu.

7. Akdağ, M., 1992. Üretim Metalürjisi, s 296-303, İzmir.

8. İsdemir, 2012. Erenco A.Ş, Sinter ve Hammadde Manipülasyon Müdürlüğü Çelikhane Çamuru Susuzlaştırma Tesisi Raporu. 